\title{
Sulama Performansının Değerlendirilmesi: Kırıkhan Sulama Birliği Örneği
}

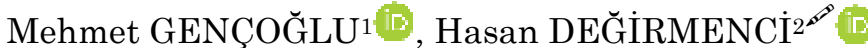 \\ ${ }^{1}$ TKGM 3109 Nolu Lisanslı Harita ve Kadastro Mühendislik Bürosu, İskenderun, Hatay, ${ }^{2}$ Kahramanmaraş Sütçü İmam Üniversitesi Ziraat \\ Fakültesi Biyosistem Mühendisliği Bölümü, Kahramanmaras \\ ${ }^{1}$ https://orcid.org/0000-0003-1824-2318, ${ }^{2}$ https://orcid.org/0000-0002-6157-816X \\ $\triangle$ : degirmenci@ksu.edu.tr
}

\section{ÖZET}

$\mathrm{Bu}$ çalışmada; Devlet Su İşleri tarafından inşa edilen ve Kırıkhan Sulama Birliğine devredilen sulama alanının performansı, su kullanım etkinliği, mali yeterlilik ve üretim etkinliği göstergeleri ile değerlendirilmiştir. Değerlendirmede; 2008-2013 yıllarına ilişkin Kırıkhan sulama birliği verileri kullanılmıştır. Çalışmada elde edilen sonuçlara göre; 2008 ve 2013 yıllarında sırasıyla birim sulama alanına dağıtılan sulama suyu miktarı $3735 \mathrm{~m}^{3} \mathrm{ha}^{-1}$ ve $16651 \mathrm{~m}^{3} \mathrm{ha}^{-1}$, birim sulanan alana dağıtılan toplam sulama suyu miktarı $5496 \mathrm{~m}^{3}$ ha-1 ve $13684 \mathrm{~m}^{3} \mathrm{ha}^{-1}$, ylllı su temini oranı 0.70 ve 1.42 'dir. Mali yeterlilik oranı en düşük 2008 yılında $\% 57,5$ en yüksek 2010 yılında $\% 108,3$, birim sulama alanına düşen işletme bakım yönetim masrafları en düşük 2010 yılında $81.52 \$$ ha $^{-1}$ en yüksek ise 2009 yılında $141.96 \$$ ha $^{-1}$, çalışan her bir personele düşen toplam ylllık masraf en düşük 2012 yılında 10055.19 \$ kişi $i^{-1}$ en yüksek ise 2013 yılında 20183.23 \$ kişi $^{-1}$ ve su ücreti toplama performansı ise \%34,42-92,08 oranında gerçekleşmiştir. Birim sulama alanına karşılık elde edilen gelir 5284247 \$ ha-1; sulanan birim alana karşılık elde edilen gelir 770-3719 \$ ha $^{-1}$; şebekeye alınan birim sulama suyuna karşılık elde edilen gelir 0.009-0.041 $\$ \mathrm{~m}^{-3}$ ve sulama oranı ise \%33-89 arasında gerçekleşmiştir.

\section{Assessment of Irrigation Performance: A Case Study of Kırıkhan Irrigation Association}

\section{ABSTRACT}

In this study; an irrigation project built by DSI (State Hydraulic Works) and transferred to Kırıkhan Water Users' Association (WUA) was chosen as a material to assess irrigation performance including water use, financial and production efficiency indicators. Data between 2008 and 2013, obtained from the WUA, was used. As a result of study; per unit irrigation water supplied to users per unit irrigated area was $3735 \mathrm{~m}^{3} \mathrm{ha}^{-1}$ and $16651 \mathrm{~m}^{3} \mathrm{ha}^{-1}$, per unit irrigation water supplied to users per unit command area was $5496 \mathrm{~m}^{3} \mathrm{ha}^{-1}$ and 13684 $\mathrm{m}^{3} \mathrm{ha}^{-1}$, relative water supply was 0.70 and 1.42 in 2008 and 2013 , respectively. The lowest (57.5\%) and the highest (108.3\%) value of financial efficiency were found in 2008 and 2010, respectively. Operation, maintenance and management cost per unit command area was the lowest (81.52 $\left.\$ \mathrm{ha}^{-1}\right)$ in 2010 and the highest (141.96\$ $\mathrm{ha}^{-1}$ ) in 2009. Cost per person was lowest (10055.19 $\$$ person $\left.^{-1}\right)$ in 2012 and the highest (20183.23 $\$$ person $\left.^{-1}\right)$ in 2013 . Water charge collection performance was changed from $34.42 \%$ to $92.08 \%$ during the study years. Output per unit command area ranged between 528-4247 $\$$ ha 1 , output per unit irrigated area was 770-3 719 $\$ \mathrm{ha}^{-1}$, output per unit water consumed was $0.009-0.041 \$ \mathrm{~m}^{-3}$ and irrigation ratio changed between $33-89 \%$.
Araştırma Makalesi

Makale Tarihçesi

Geliş Tarihi : 11.12 .2018

Kabul Tarihi : 04.02.2019

Anahtar Kelimeler

Sulama

Sulama şebekesi

Sulama birliği

Sulama performansı

To Cite : Gençoğlu M, Değirmenci H 2019. Sulama Performansının Değerlendirilmesi: Kırıkhan Sulama Birliği Örneği. KSÜ

\section{Research Article}

$\begin{array}{ll}\text { Article History } & \\ \text { Received: } & 11.12 .2018 \\ \text { Accepted: } & 04.02 .2019\end{array}$

Keywords
Irrigation
Irrigation scheme
Water user association
Irrigation performance

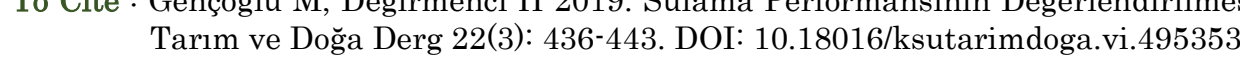




\section{GİRİ̧̧}

Artan nüfus, yüksek kentleşme oranı ve sanayi yatırımları; tarımsal, endüstriyel ve içme suyu kullanıcılarının talepleri arasında ciddi bir rekabet doğurmuştur. Su talebinin tüm sektörlerde gidere artması nedeniyle, suyu en fazla tüketen tarımsal sulama şebekelerinde suyun etkin kullanımı giderek daha fazla sorgulanır duruma gelmiştir. Ancak, sulamanın tekniğine uygun yapılamaması ya da aşırı su kullanımı nedeniyle erozyon, yüksek taban suyu, sodyumluluk, tuzluluk ve drenaj gibi sulu tarımın sürdürülebilirliğini tehdit eden ciddi çevresel sorunlar ortaya çıkmaktadır. Bu nedenlerden dolayı, tüm dünyada sulama şebeke performanslarının yükseltilmesi gerekmektedir. Sulama şebeke performanslarının belirlenmesinde karşılaştırma göstergeleri kullanılmakta ve performansin artırılması için araştırmalar yapılmaktadır.

Birçok ülkede; sulama şebekelerinin daha etkin, verimli ve yerinden yönetimi, işletme ve bakım giderlerinin azaltılması gibi hedeflerinin gerçekleştirilmesine yönelik olarak, kullanıcılara devredilmesi çalışmaları yürütülmüştür. Sulama şebekelerinde işletme-bakım ve yönetim sorumluluğunun su kullanıcı örgütlerine devri birçok ülkede gerçekleştirilmiştir (Vermillion ve Sagardoy, 1999; Vermillion, 2000). Ülkemizde sulama şebekelerinin işletme bakım ve yönetim sorumluluğunun su kullanıcı örgütlerine devir çalışmalarına 1993 yılında başlanmıştır. Böylelikle Dünya Bankasından alınan destekle DSİ tarafından inşa edilen ve işletilen sulama şebekelerinin yönetimi sulama birliklerine, sulama kooperatiflerine, belediyelere ve köy tüzel kişiliklerine devredilmiştir.

Dünya'da ve ülkemizde sulama performansının değerlendirilmesine ilişkin göstergeler geliştirilmiş ve birçok çalışma yapılmıştır. Sulama performans değerlendirmesi için su kullanımı, tarımsal üretim, mali performans ve sistem performansı üzerine çok sayıda gösterge geliştirilmiştir. Abernethy (1986) suyun eşitlik, güvenilirlik ve etkinlik, Plusquellec ve ark. (1990) su kullanım etkinliği, bitki deseni ve üretim değeri, Molden ve Gates (1990) ana kanal, sekonder kanal ve tersiyer kanal düzeyinde su kullanımının yeterlilik, etkinlik, güvenilirlik ve eşitlik, Bos ve ark. (1994) su dağıtım performansı, tarımsal etkinlik performansı, sosyo-ekonomik ve çevresel performansı, Meinzen-Dick (1995) sulama zamanının belirlenmesi ve yönetimi, Malano ve ark. (2004), su kullanım ve dağıtım etkinliği, finansal yeterlilik, üretim değeri ve çevresel etkinlik ve Molden ve ark. (1998) şebekeler arasında karşılaştırma yapabilmek için birim alan ve su kullanımı karşılığında elde edilen eşdeğer üretim değeri göstergelerini geliştirmişlerdir. Yercan ve ark. (2004), Gediz nehri havzasında 8 sulama şebekesini, Eliçabuk ve Topak (2017), Gevrekli Sulama Birliğini, Akçay (2016), Aydın ilinde faaliyet gösteren 25 sulama kooperatifini, Değirmenci ve ark. (2017) Türkiye'nin değişik havzalarında sulama birlikleri tarafindan işletilen sulama şebeke alanı 20000 ha'dan büyük 14 sulama şebekesini, Kuşcu ve ark. (2009) Karacabey sulama şebekesinin başarısını, Bareng ve ark. (2015) Filipinler'de sulama birlikleri tarafından işletilen dört sulama şebekesini ve Corcoles ve ark. (2010) İspanya'da 7 sulama birliğinin sistem başarısını geliştirilen göstergeleri kullanarak değerlendirmişlerdir.

$\mathrm{Bu}$ çalışma; Hatay bölgesinde yer alan Kırıkhan sulama alanında faaliyet gösteren sulama birliğinin su kullanım etkinliğini, mali yeterlilik düzeyini ve üretim etkinliğini ilgili göstergelerle değerlendirilmesini, araştırma çıktılarının ülkemiz sulama birliklerinin işletim başarısına ve bu konudaki literatüre katkı sağlamayı amaçlamaktadır.

\section{MATERYAL ve METOT}

$\mathrm{Bu}$ araştırma Hatay İli Kırıkhan İlçesinde bulunan toplam 11 köyün (Kodallı, Ilıkpınar, Karamağara, Alaybeyli, Reşatlı, Aktutan, Güzelce, Karadurmuşlu, Karaçağıl, Karmankaşı ve Mahmutlu) tarım arazilerini içine alan Kırıkhan Sulama Birliği sulama alanında yapılmıştır. Sulama şebekesinin haritası Şekil 1'de verilmiştir. Sulama performans göstergelerinin hesaplanmasında 2008-2013 yıllarına ilişkin Kırıkhan sulama birliği verileri kullanılmıştır. Amik Ovasının kuzey doğusunda bulunan Kırıkhan sulaması 1983 yılında tamamen sulamaya açılmıştır. Sulama şebeke toplam alanı 7300 ha olup, sulama suyu Karasu Çayı Kamışlar regülatöründen temin edilmektedir. Sulama sahasında bölge çiftçileri I. ve II. ürün ekimi yapmaktadırlar. Sulama şebekesinde 2008-2013 yıllarında gerçekleşen bitki deseni Çizelge 1 'de verilmiştir.

Sulama şebeke alanı Akdeniz iklimi özelliği taşımaktadır. Yazlar sıcak ve kurak, kışlar ise yağışlıdır. Kırıkhan uzun yıllık ortalama yağış miktarı $1130.8 \mathrm{~mm}$, uzun yıllık ortalama sicaklık $18.3^{\circ} \mathrm{C}$ ve ortalama nem \%63.7'dir. Sulama alanında eğim \%2-5 arasında değişmektedir.

Çizelge 1. Sulama şebekesinde gerçekleşen bitki deseni

\begin{tabular}{ccccccc}
\hline Yıllar & \multicolumn{6}{c}{ Bitki dağılımı(\%) } \\
\cline { 2 - 7 } & \multirow{2}{*}{ Pamuk } & Hububat & Mısır & Bostan & Sebze & Ür. \\
\hline 2008 & 42 & 34 & 12 & 6 & 2 & 6 \\
2009 & 41 & 26 & 8 & 4 & 3 & 70 \\
2010 & 44 & 25 & 16 & 3 & 1 & 32 \\
2011 & 58 & 12 & 17 & 3 & 8 & 22 \\
2012 & 35 & 26 & 26 & 4 & 1 & 24 \\
2013 & 39 & 27 & 19 & 3 & 1 & 35 \\
\hline
\end{tabular}




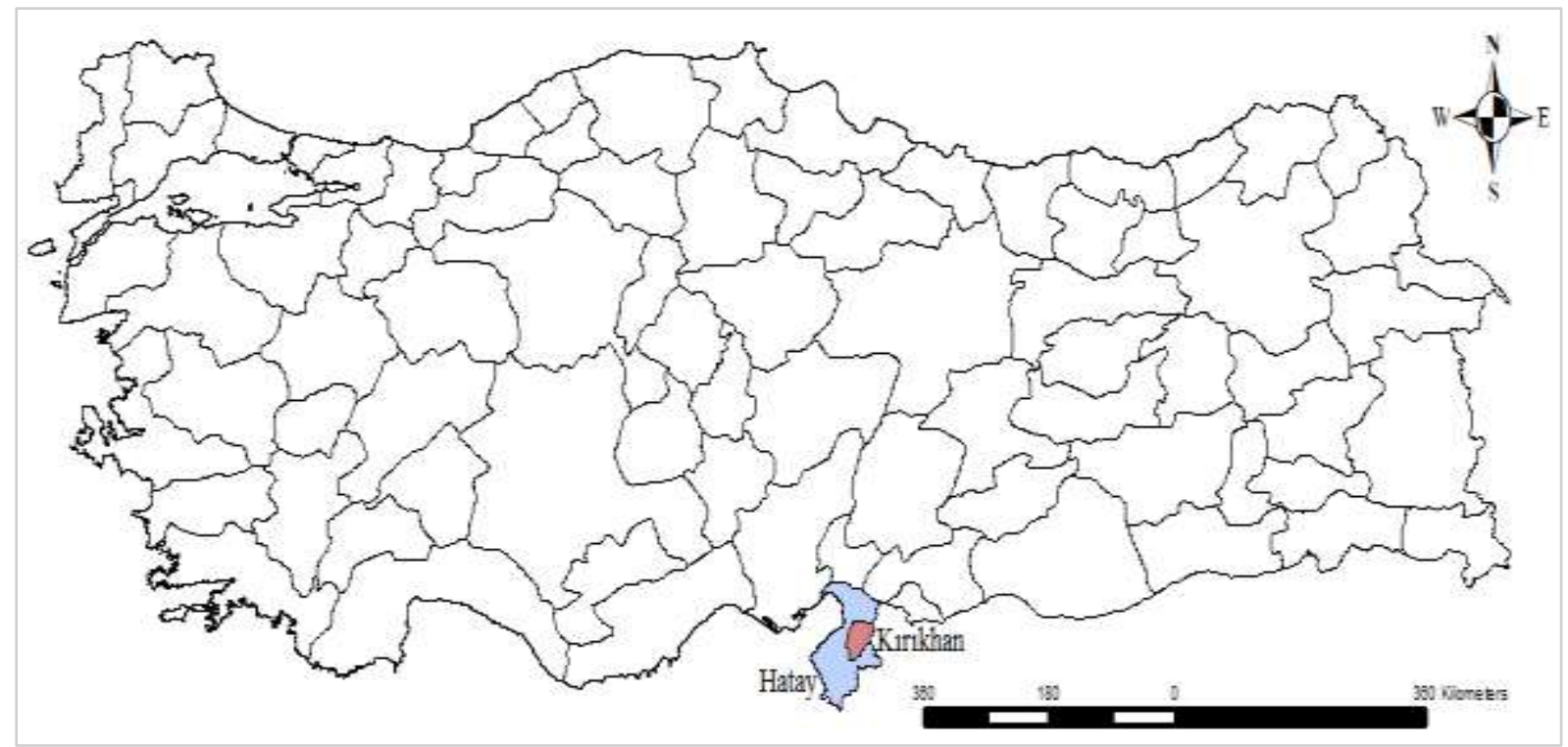

Şekil 1. Araştırma alanının konumu

Çizelge 2. Sulama performans göstergeleri

\begin{tabular}{|c|c|c|}
\hline Alan & Kod & Performans Göstergesi \\
\hline ;: & $\mathrm{A}$ & $\begin{array}{l}\text { Birim sulama dağıtılan yıllık sulama suyu miktarı }\left(\mathrm{m}^{3}\right. \\
\left.\mathrm{ha}^{-1}\right)\end{array}$ \\
\hline छ & B & $\begin{array}{l}\text { Birim sulanan alana dağıtılan yıllık sulama suyu miktarı } \\
\left(\mathrm{m}^{3} \mathrm{ha}^{-1}\right)\end{array}$ \\
\hline 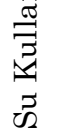 & $\mathrm{C}$ & Yıllık su temin oranı \\
\hline
\end{tabular}

D Mali yeterlilik oranı (\%)

Eşitlik

$$
\begin{gathered}
=\frac{\text { Toplam su miktarı }}{\text { Sulama alanı }} \\
=\frac{\text { Toplam su miktarı }}{\text { Sulanan alan }} \\
=\frac{\text { Toplam su miktarı }}{\text { Toplam sulama suyu ihtiyacı }}
\end{gathered}
$$

$=\frac{\text { Toplanan su ücreti }}{\text { Toplam İBY masrafl }} X 100$

E Bakım masraflarının gelire oranı (\%)

$=\frac{\text { Toplam bakım masrafi }}{\text { Toplam su ücreti }} X 100$

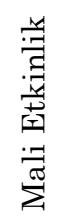

F Birim sulama alanına düşen toplam işletme -bakım yönetim masrafi $\left(\$ \mathrm{ha}^{-1}\right)$

$$
=\frac{\text { Toplam İBY masrafı }}{\text { Sulama alanı }}
$$

$\mathrm{G} \quad \mathrm{Su}$ dağıtımında istihdam edilen her bir kişiye düşen toplam masraf $\left(\$\right.$ kişi $\left.^{-1}\right)$

$=\frac{\text { Toplam personel gideri }}{\text { Toplam personel sayıs }}$

H Su ücreti toplama performansı (\%)

$=\frac{\text { Toplam tahsilat }}{\text { Toplam tahakkuk }} X 100$

J 1000 ha alana düşen personel sayısı (kişi 1000 ha $^{-1}$ )

$=\frac{\text { Toplam personel sayısı }}{\text { Sulama alanı }}$

K Birim sulama alanına karşılık elde edilen gelir ( $\$ \mathrm{ha}^{-1}$ )

$=\frac{\text { Toplam üretim değeri }}{\text { Sulama alanı }}$

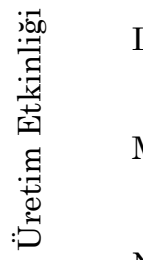

L Sulanan birim alana karşılık elde edilen gelir ( $\$ \mathrm{ha}^{-1}$ )

$=\frac{\text { Toplam üretim değeri }}{\text { Sulanan alan }}$

M Şebekeye alınan birim sulama suyuna karşılık elde edilen gelir $\left(\$ \mathrm{~m}^{-3}\right)$

$=\frac{\text { Toplam üretim değeri }}{\text { Şebekeye alınan su miktarı }}$

N Sulama oranı (\%)

$$
=\frac{\text { Sulanan alan }}{\text { Sulama alanı }} X 100
$$


Çalışmada Malano ve ark. (2004) tarafından geliştirilen su kullanım etkinliği, mali etkinlik ve üretim etkinliği performans göstergeleri kullanılmıştır. Performans göstergeleri ve hesaplama yöntemleri Çizelge 2'de verilmiştir. Araştırmada sulanan alan I. ürün ve II. ürün ekim alanının toplamı alınmıştır. Ürün ve Sulama şebekelerinin yıllar bazında araştırma sonuçlarının karşılaştırmalarının yapılabilmesi için Türk Lirasının dolar karşılığ hesaplanmasında Merkez Bankasının ilgili yıldaki dolar kuru ortalaması alınmıştır.

\section{BULGULAR ve TARTIŞMA}

\section{Su Kullanım Etkinliği Göstergeleri Sonuçları}

Sulama alanında su kullanım etkinliğine ilişkin 20082013 yllları için hesaplanan performans göstergeleri bulguları Çizelge 3’te verilmiştir.

\section{Çizelge 3. Su kullanım etkinliği göstergeleri}

\begin{tabular}{llll}
\hline Ylllar & A & B & C \\
\hline 2008 & 3735 & 5496 & 0.70 \\
2009 & 7163 & 10540 & 1.97 \\
2010 & 13623 & 13934 & 1.85 \\
2011 & 8506 & 11538 & 1.16 \\
2012 & 14467 & 14238 & 1.27 \\
2013 & 16651 & 13684 & 1.42 \\
\hline
\end{tabular}

A: Birim sulama alanına dağıtılan yıllık sulama suyu miktarı $\left(\mathrm{m}^{3} \mathrm{ha}^{-1}\right)$; B: Birim sulanan alana dağıtılan ylllk sulama suyu miktarı $\left(\mathrm{m}^{3} \mathrm{ha}^{-1}\right)$; $\mathrm{C}$ : Yıllık su temin oranı

Çizelge 3'te verilen birim sulama alanına dağıtılan yıllık sulama suyu miktarı (A) en düşük 2008 yılında $3735 \mathrm{~m}^{3} \mathrm{ha}^{-1}$ ve en yüksek 2013 yllında $16651 \mathrm{~m}^{3} \mathrm{ha}^{-1}$ olarak gerçekleşmiştir. Sulama şebekesinde 2013 yılında I. ürün ve II. ürün olmak üzere toplam 5074 ha alanda sulama yapılmıştır. Bu nedenle 2013 yılında sulama alanına dağıtılan su miktarı çok yüksek bulunmuştur. Sulanan alana dağıtılan yıllık sulama suyu miktarı (B) en düşük 2008 yılında $5496 \mathrm{~m}^{3}$ ha-1 ve en yüksek 2012 yllında $14238 \mathrm{~m}^{3} \mathrm{ha}^{-1}$ ve ylllı su temini oranı (C) ise en düşük 2008 yllında 0.70 ve en yüksek 2009 yılında 1.97 olurken ortalama olarak 1.40 olarak gerçekleşmiştir. Su temin oranının düşük olduğu yıllarda sulama oranı da düşük gerçekleşmiştir. Eliçabuk ve Topak (2017) çalışmalarında; Konya Gevrekli sulama şebekesinde birim alana dağgtılan yıllık sulama suyu miktarını en düşük 2008 yılında $665 \mathrm{~m} \mathrm{ha}^{-1}$ ve en yüksek 2013 yılında $1301 \mathrm{~m} \mathrm{ha}^{-1}$, birim sulanan alana dağıtılan yıllık sulama suyu miktarını en yüksek 2009 yılında $5273 \mathrm{~m} \mathrm{ha}^{-1}$ ve en düşük 2008 yllında $2577 \mathrm{~m} \mathrm{ha}^{-1}$, yıllık su temini oranını en düşük 2008 yılında 0.51 ve en yüksek 2009 yılında 1.04 olarak belirlemişlerdir. Uçar (2011) Isparta'da bulunan 10 sulama şebekesinde toplam su temin oranının 0.60 ile 7.32 arasında değiştiğini belirlemiştir. El-Agha ve ark. (2011), Misir'da Nil deltasinda bulunan Meet Yazid sulama şebekesinde su temin oranını Nisan ayında 0.92, Kasım ayında 2.38 ve ortalama 1.5 olarak bulmuşlardır. Levine (1982)'e göre, su temini oranının 1 olması durumunda sulama şebekesine ihtiyaç kadar su alındığını, 1'den küçük olması durumunda yetersiz su temin edildiğini, 1'den büyük olması durumunda ise sulama şebekesine fazla su alındığını ifade edilmektedir. Buna göre sulama alanına verilen suyun 2008 yılında ihtiyacın altında, 2009-2013 yılları arasına ise ihtiyacın üzerinde olduğu bulunmuştur.

\section{Mali Etkinlik Göstergeleri Sonuçları}

Sulama alanı mali etkinlik göstergeleri sonuçları Çizelge 4'te verilmiştir.

Mali yeterlilik oranı (D), sulama sebekelerinde kullanicilardan toplanan sulama suyu ücretlerinin, o yıl yapılan işletme ve bakım masraflarını karşılayıp karşılayamadığının bir göstergesidir. Çiftçilerden toplanan toplam sulama suyu ücreti ve toplam işletme, bakım ve yönetim masrafları verilerine göre bulunan mali yeterlik oranı; \%57.5 ile en düşük 2008 yılında, \% 108.3 ile en yüksek 2010 yılında bulunmuştur. Çakmak (2002a) Ceylanpınar İkicırcıp sulama şebekesinden sorumlu olan sulama birliğinde mali yeterlilik oranını \%105-211 arasında belirlemiştir. Beyribey (1997) ise mali yeterlilik oranının \%21ile \%91 arasinda ve ortalama olarak ise \%65 olduğunu belirlemiştir.

Çizelge 4. Mali etkinlik göstergeleri

\begin{tabular}{lllllll} 
Ylllar & D & E & F & G & H & J \\
\hline 2008 & 57.49 & 2.12 & 119.21 & 13851.24 & 34.42 & 6 \\
2009 & 78.53 & 23.35 & 141.96 & 13395.06 & 65.75 & 5.9 \\
2010 & 108.30 & 2.41 & 81.52 & 13809.25 & 57.35 & 3.9 \\
2011 & 92.67 & 2.13 & 106.83 & 10748.94 & 92.08 & 3.7 \\
2012 & 94.85 & 26.28 & 102.48 & 10055.19 & 52.02 & 3.8 \\
2013 & 88.08 & 33.18 & 124.13 & 20183.23 & 66.11 & 2.6 \\
\hline
\end{tabular}

D: Mali yeterlilik oranı (\%); E: Bakım masrafının gelire oranı (\%); F: Birim alana düşen toplam işletme -bakım yönetim masrafı ( $\$$ ha $\left.^{-1}\right)$; G: Su dağıtımında çalışan her bir kişiye düşen toplam masraf ( $\$$ kişi-1); H: Su ücreti toplama performansı (\%); J: 1000 ha alana düşen personel sayısı (kişi 1000 ha-1) 
Molden ve Gates (1990), çeşitli ülkelerde farklı sulama şebekelerinde mali yeterlilik oranının \%28 ile 139 arasında değisstiğini, su kullanıcı örgütlerinde bu değerin \%100'e yakın olduğunu, kamu sulama şebekelerinde ise \%30-50 arasında değiştiğini belirlemişlerdir.

$\mathrm{Bu}$ çalışmada hem yıl bazında hesaplanan değerler hem de ortalama değerler, çiftçilerden alınan su ücretlerinin işletme, bakım ve yönetim masraflarını karşılamada yeterli olmadığını göstermektedir.

Bakım masrafının gelire oranı (E) en düşük 2008, 2010, 2011 yillarinda sirasiyla \%2.12, 2.41 ve 2.13 olarak belirlenmiştir. E oranı en yüksek ise \%33.18 olarak 2013 yılında saptanmıştır. Dolayısıyla çalışmanın yapıldığı beş yıllık süreç içerisinde ortalama bakım masrafinın gelire oranı \%14.91 olarak gerçekleşmiştir. Cin ve Çakmak (2017)'ın Beypazarı Başören Sulama Kooperatifinde bakım masraflarının gelire oranını \% 14 olarak bulmuşlardır. Phadnis ve Kulsreshtha (2011) Hindistan Samrat Ashok Sagar sulama şebekesinde faaliyet gösteren 19 sulama birliğinde bakım masraflarının gelire oranını \%2-15 arasında hesaplamışlardır.

Birim alana düşen toplam işletme-bakım-yönetim masrafi (F) en düşük 2010 yılında $81.52 \$$ ha $^{-1}$ ve en yüksek 2013 yılında $124.13 \$$ ha $^{-1}$ bulunmuştur. Arslan ve Değirmenci (2018) Kahramanmaraş Sol Sahil sulama birliğinde birim alana düşen toplam işletme bakım yönetim masrafını 89.26 $\$$ ha $^{-1}$ olarak bulmuştur. Alcon ve ark. (2017) İspanya'da üzerinde çalıştıkları 5 farklı sulama şebekesinde birim alana düşen toplam işletme-bakım-yönetim masrafını 20022010 yılları arasında 400 ile $1300 €$ ha $^{-1}$ arasında, ortalama değeri ise $1014 € \mathrm{ha}^{-1}$ olarak belirlemişlerdir. Literatür çalışmaları karşılaştırıldığında ülkemizde F göstergesinin diğer ülkelere göre oldukça düşük gerçekleştiği görülmektedir.

$\mathrm{Su}$ dağıtımında istihdam edilen her bir kişiye düşen masraf (G) en düşük 2012 yılında 10055.19 \$ ve en yüksek 2013 yılında 20183.23 \$ olmuştur. Nalbantoğlu ve Çakmak (2007) Akıncı sulamasında yapmış oldukları araştırmada, su dağıtımında istihdam edilen her bir kişiye düşen toplam masraf; en düşük 1999 yllında 1091.09 \$ ve en yüksek 2005 yılında $8658.84 \$$ olarak bulmuşlardır. Malano ve ark. (2004) çeşitli ülkelerde yapmış oldukları bir çalışmada her bir çalışana düşen masrafi 84 nolu şebekede 987.55 \$ kişi1, 89 nolu işletmede ise $13602 \$$ kişi $^{-1}$ olarak belirlemişlerdir. Kırıkhan sulama birliğinde elde edilen değerler yapılan diğer çalışmalara göre oldukça yüksek olarak belirlenmiştir.

$\mathrm{Su}$ ücreti toplama performansı (H) 2011 yılında \%92.08 ile en yüksek, 2008 yılında ise \%34.42 ile en düşük bulunmuştur. Kalender ve Topak (2017), Konya Ilgin sulama şebekesinde su ücreti toplama performansını değerlendirdikleri 2007-2015 yılları arasında, en düşük değeri 2013 yılında \% 83.54 ve en yüksek ise 2014 yılında \%146.97 olarak hesaplamışlardır. Djumaboev ve ark. (2017) Kuzey Özbekistan'da 12 sulama şebekesinde su ücreti toplama performansının $\% 23$ ile 57 arasında değiştiğini belirlemişlerdir. Bu çalışmada elde edilen değerler benzer çalışmalarla uyum sağlamaktadır. Su ücreti toplama performansının bazı yıllarda düşük olmasının başlıca nedenleri, ürünlerin pazar fiyatının düşük olması ve çiftçilerin su ücretini ödeme alışkanlığının olmaması söylenebilir.

1000 ha alana düşen personel sayısı (J) 2008-2013 yılları arasında en az 2013 yılında 2.6 kişi 1000 ha $^{-1}$, en fazla ise 2008 yılında 6 kişi 1000 ha $^{-1}$ olarak gerçekleşmiştir. Nalbantoğlu ve Çakmak (2007) Akıncı sulamasında yaptığı araştırmada; en çok 2004 yılında 1.2 kişi $1000 \mathrm{ha}^{-1}$ ve en az 2002 yllında 7 kişi 1000 ha 1 olduğunu, Rodriguez Diaz ve ark. (2004) İspanya Andalusia bölgesinde 5 sulama şebekesinde 1000 ha alana düşen çalışan sayısını sırasıyla 1.06, 1.40, 0.30, 0.89 ve 2.60 olarak bulmuşlardır. Bekişoğlu (1994), çeşitli ülkelerdeki sulama şebekelerinde 10000 ha alan için ortalama 30 personelin görev yaptığını, ancak bu sayının ülkemiz sulama şebekelerinin DSI tarafından yönetildiği dönemde 72.5 ile ortalamanın yaklaşık 2.5 katı olduğunu belirtmektedir. Aynı araştırmacı, birim personelce denetlenmesi gereken sulama alanının 333 ha olması gerektiğini belirlemiştir. Çalışma alanında birim alana düşen personel sayısının benzer çalışmalarla paralellik gösterdiği görülmüştür. Ancak özellikle değerlendirme periyodunun sonlarına doğru (2011-2013 yılları arasında) personel yetersizliği olduğu belirlenmiştir.

\section{Üretim Etkinliği Göstergeleri Sonuçları}

Üretim etkinliği gösterge sonuçları Çizelge 5’te verilmiştir. Birim sulama alanına karşıllı elde edilen gelir (K) en yüksek 2013 yılında $4247.15 \$$ ha $^{-1}$, en düşük ise 2009 yılında $528.78 \$$ ha $^{-1}$ gerçekleşmiştir. Büyükcangaz ve ark. (2018) Bursa bölgesinde yapmış oldukları bir çalışmada 2011-2014 yılları için 9 sulama şebekesinde birim sulama alanına karşılık elde edilen geliri ortalama $854.42 \mathrm{TL} \mathrm{ha}^{-1}$ ve standart sapmasinı ise 21.51 olarak belirlemişlerdir. Malano ve ark. (2004) çeşitli ülkelerde yapmış oldukları çalışmada; birim sulama alanına karşılık elde edilen geliri 84 nolu sulama şebekesinde en düşük 1346 en yüksek 1568 ve 89 nolu sulama şebekesinde ise en düşük 977.25 ve en yüksek $1087 \$$ ha $^{-1}$ olarak hesaplamışlardır.

Sulanan birim alana karşılık elde edilen gelir (L) en yüksek 2011 yılında $3719 \$$ ha $^{-1}$ ve en düşük 2009 yılında $770 \$$ ha $^{-1}$ olmuştur. Akkuzu ve Pamuk Mengü (2012) Gediz havzasında faaliyet gösteren 10 sulama birliğinde 2002-2008 yılları için sulanan birim alana karşıllk elde edilen gelir değerlerini 2136 ile 9066 \$ ha 1 arasında hesaplamışlardır. Birliklerin 2002-2008 
yılları arası ortalaması ise 3290 ile $4829 \$$ ha $^{-1}$ arasındadır.

Şebekeye alınan birim sulama suyuna karşılık elde edilen gelir (M) 0.009-0.041 $\$ \mathrm{~m}^{-3}$ arasında değişmiştir. Çakmak (2002b), Kızılırmak Havzasında yer alan 8 sulama birliğinde 1999-2000 yıllarına ilişkin tüketilen birim sulama suyuna karşllık elde edilen geliri $0.02^{-}$ $1.88 \$ \mathrm{~m}^{-3}$ arasında belirlemiştir. Kapan (2010) Asartepe sulama birliğinde tüketilen birim sulama suyuna karşılık elde edilen gelir, en yüksek 2006 yılında $13.951 \mathrm{TL} \mathrm{m}^{-3}$, en düşük ise 2007 yılında 5.804 TL $\mathrm{m}^{-3}$ olarak hesaplamıştır. Rodriguez Diaz ve ark. (2004) İspanya Andalusia bölgesinde 5 sulama şebekesinde birim sulama suyuna karşılık elde edilen geliri sirasiyla $1.09,0.88,1.31,0.60$ ve $0.57 \$ \mathrm{~m}^{-3}$ olarak hesaplamışlardır.

Sulama oranı (N) en düşük 2008 ve 2009 yıllarında gözlemlenmiş olup \%33'tür. En yüksek sulama oranı değeri ise \%89 ile 2013 yılında gerçekleşmiştir. Eliçabuk ve Topak (2017) Konya Gevrekli sulamasında sulama oranını 2008-2013 yıllarında \%21.8 ile \%35.1 arasında bulmuşlardır. Garcia-Bolanos ve ark. (2011) yapmış oldukları çalışmada; Moritanya'da orta ve küçük büyüklükte 22 sulama şebekesinin yarısından fazlasında sulama oranı \%66'yı geçmemiştir. Ülkemizde sulama şebekelerinin ortalama sulama oranı \%62'dir. Çalışma alanında her geçen yıl sulama oranının arttığı görülmüştür.

Çizelge 5. Üretim etkinliği sonuçları

\begin{tabular}{lllll} 
Ylllar & K & L & M & N \\
\hline 2009 & 528 & 770 & 0.009 & 33 \\
2010 & 3611 & 3663 & 0.033 & 66 \\
2011 & 2781 & 3719 & 0.041 & 52 \\
2012 & 3448 & 3334 & 0.032 & 76 \\
2013 & 4247 & 3454 & 0.034 & 89 \\
\hline
\end{tabular}

$\mathrm{K}$ :Birim sulama alanına karşılık elde edilen gelir ( $\$$ ha 1); L:Sulanan birim alana karşlılk elde edilen gelir ( $\$$ ha $^{-1)} \mathbf{M}$ : Şebekeye alınan birim sulama suyuna karşıllı elde edilen gelir $\left(\$ \mathrm{~m}^{-3}\right) ; \mathrm{N}$ : Sulama oranı (\%)

\section{SONUÇ}

Kırıkhan sulama birliğinde su dağıtım performansı göstergesi olarak incelenen su temin oranı 2008 yilinda 0.70 olup sulama alanina verilen suyun yetersiz olduğu tespit edilmiştir. Diğer yıllarda bu oran 1.16 ile 1.97 arasında değişim göstermekte olup sulama alanına ihtiyaç fazlası suyun verildiği dolayısıyla da suyun etkin kullanılmadığı görülmektedir.

Kullanıcılardan toplanan su ücretleri işletme, bakım, yönetim masrafları incelendiğinde mali yeterlilik incelemesinde o yll toplanan su ücretleri ile sistemin bakım ve işletme giderleri oranı karşılaştırılması yapılabilmekte olup, çalışma alanında bu oran en düşük 2008 yılında \% 57.49 ve en yüksek 2010 yılında
\%108.3 olarak elde edilirken ortalama değer \%86.65 olarak bulunmuştur. $\mathrm{Bu}$ veriler çalışma alanında toplanan su ücretlerinin işletme ve bakım masraflarını karşılamadığı ve su ücreti toplama performansının düşük olduğunu göstermektedir.

Araştırma alanında kullanıcılardan toplanan toplam su ücretinin toplam bakım masrafına bölünmesi ile elde edilen bakım masrafinın gelire oranı ile elde edilen değer, sistemin bakım masraflarının karşılanabilmesi oranını göstermektedir. Buna göre bakım masrafının gelire oranı değerinin en düşük 2008, 2010, 2011 yıllarında gerçekleştiği ve yaklaşık $\% 2$ oranında olduğu görülmüş olup, en yüksek ise 2013 yılında \%33 olarak pay ayrıldığı saptanmıştır. Buna göre, araştırma alanında kullanıcılardan toplanan toplam su ücreti toplam bakım masraflarını karşılamaktadır.

Çalışma alanını oluşturan Kırıkhan Sulama Birliğinin su dağıtımı, işletme ve bakım konularında performansının oldukça kötü durumda olduğu görülmüştür. Bununla birlikte sulama birliğinin en büyük sorunu; sulama tesislerinin çok eski, yıpranmış ve hatta bazı kesimlerinin kullanılamaz durumda olmasıdır. Bakım masraflarının gelire oranı ele alındığında bazı yıllarda gerçekleşen düşük değerlerin sistemin etkin kullanılması bakımından kayıplara neden olan bir etken olduğu gözlenmektedir. Diğer taraftan su ücretlerinin toplanmasinda da genel olarak ortalamalara yakın oranlara ulaşılmış olmakla birlikte, düşük değerler görülmekte, bu da diğer performans değerlerini etkileyen önemli bir unsur olarak değerlendirilmektedir.

Sistemde bulunan tüm olumsuzluklara rağmen, sistemde bulunan eksikliklerin sulama bakım hizmetleri ile düzeltilmesi veya yenilenmesi gereken kısımların yenilenmesi ile sistemin daha kullanılabilir hale getirilerek su kaybının en aza indirilmesi sonucunda, suyun sulamada daha etkin kullanımı sağlanabilir. Sulama suyunun bitkilere yeteri kadar ve gerektiği zamanda uygulanması ilkesinden hareketle, tarımsal faaliyetler içinde önemli bir yere olan sahip olan suyun etkin kullanılması ve su kaybının en aza indirilmesi yönünde çiftçiler mutlaka bilinçlendirilmelidir. Çiftçiler ile sulama birliklerinin uyumu ve ortak çıkarları doğrultusunda faaliyet gösteren bir tüzel kişilik olduğunun kabulünün sağlanması ile sistemin daha etkin ve verimli olarak kullanılabileceği düşünülmektedir.

Sonuç olarak; birliklerin kuruluş ve işleyiş amaçlarının çiftçilere yönelik olduğu ve çiftçilerinde bu birliklerin birer parçası oldukları gerçeğini kabullendirecek çalışmalar yapılmalı, kısıtlı olan suyun etkin kullanımı için de sulama tesislerinin yenilenmesi, bakımlarının tam yapılması gerekmektedir. 


\section{KAYNAKLAR}

Abernethy CL 1986. Performance measurement in canal water management: a discussion. London, UK: ODI. 25p. (ODI/IIMI Irrigation Management Network 86/2d)

Akçay S 2016. Aydın İli Sulama Kooperatiflerinde Su Sağlama Oranlarının Belirlenmesi. Tekirdağ Ziraat Fakültesi Dergisi,13(2) :135-143

Akkuzu E, Pamuk Mengü G 2012. Aşağı Gediz Havzası Sulama Birliklerinde Karşılaştırmalı Performans Göstergeleri İle Sulama Sistem Performansinın Değerlendirilmesi. Ege Üniv. Ziraat Fak. Derg., 49 (2): 149-158.

Alcon F, Bastida PAG, Garcia MS, Alvarez VM, Gorriz BM., Baille A. 2017. Explaining the Performance of Irrigation Communities in a Waterscarce Region. Irrig Sci., 35:193-203.

Arslan F, Değirmenci H 2018. Sulama Şebekelerinin işletme-bakım ve yönetim modernizasyonunda RAP-MASSCOTE yaklaşımı: Kahramanmaraş Sol Sahil Sulama şebekesi örneği. Atatürk Üniv. Ziraat Fak. Derg., 49(1): 45-51

Bareng JLR, Balderama OF, Alejo LA 2015. Analysis of Irrigation Systems Employing Comparative Performance Indicators: A Benchmark Study for National Irrigation and Communal Irrigation Systems in Cagayan River Basin. Journal of Agricultural Science and Technology A, 5: 325-335.

Bekişoğlu Ş 1994, Türkiye'deki Sulama Sistemlerinin Mevcut Durumu, İşletme ve Bakım Sorunları. Su ve Toprak Kaynaklarının Geliştirilmesi Konferans Bildirgeleri. Bayındırlık ve İskan Bakanlığ Genel Müdürlüğü, 2, 579-586.

Beyribey M 1997. Devlet Sulama Şebekelerinde Sistem Performansının Değerlendirilmesi. A.Ü. Ziraat Fakültesi Yayın No: 1480, Bilimsel Araştırmalar ve İncelemeler. 813. Ankara, 88s.

Büyükcangaz H, Değirmenci H, Kartal S 2018. Bursa Bölgesi Sulama Şebekelerinin İstatistiksel Yöntemlerle Değerlendirilmesi. Türk Tarım ve Doğa Bilimleri Dergisi 5(4): 501-508.

Cin S, Çakmak B 2017. Assessment of Irrigation Performance in Başören Irrigation Cooperative Area of Beypazarı, Ankara. JAFAG, 34(2): 10-19.

Corcoles JI, Juan JA, Ortega JF, Tarjuelo JM, Moreno MA 2010. Management evaluation of Water Users Associations using benchmarking techniques. Agricultural Water Management 98(1): 1-11.

Çakmak B 2002a. Ceylanpınar İkicırcıp Sulama Birliği'nde Sulama Sistem Performansının Değerlendirilmesi. Harran Üniv. Ziraat Fakültesi Dergisi, 7(1-2):1-9.

Çakmak B 2002b. Kızılırmak Havzası Sulama Birliklerinde Sulama Sistem Performansının Değerlendirilmesi. KSÜ Fen ve Mühendislik Dergisi, 5(2): 130-141.

Değirmenci H, Tanrıverdi Ç, Arslan F 2017. Aşağı Seyhan Ovası Sulama Birliklerinin Kümeleme
Analizi ile Karşılaştırılması. KSÜ Doğa Bil. Derg., 20(4): 326-333.

Djumaboev K, Hamidov A, Anarbekov O, Gafurov Z, Tussupova K 2017. Impact of Institutional Change on Irrigation Management: A Case Study from Southern Uzbekistan. Water 9(6): 419.

El-Agha DE, Molden D, Ghanem AM 2011. Performance assessment of irrigation water management in old lands of the Nile delta of Egypt. Irrigation and Drainage Systems, 25(4): 215-236.

Eliçabuk C, Topak R 2017. Gevrekli Sulama Birliğiinde Sulama Performansının Değerlendirilmesi. Selçuk Tar. Bi.l Der., 3(2): 191-199.

Garcia-Bolanos M, Borgia C, Poblador N, Dia M, Seyid OMV, Mateos L 2011. Performance assessment of small irrigation schemes along the Mauritanian banks of the Senegal River. Agricultural Water Management, 98(7): 1141-1152.

Kalender MA, Topak R 2017. Irrigation Performance of Ilgin Plain Irrigation Association. Selcuk J. Agr. Food Sci., 31(2): 59-67.

Kapan E 2010. Asartepe Sulama Birliğinde Sulama Performansının Karşılaştırmalı Değerlendirilmesi. Ankara Üniversitesi Fen Bilimleri Enstitüsü, Tarımsal Yapılar ve Sulama Ana Bilim Dalı, Yüksek Lisans Tezi, $47 \mathrm{~s}$.

Kuşcu H, Bölüktepe FE, Demir AO 2009. Performance assessment for irrigation water management: A case study in the Karacabey irrigation scheme in Turkey African Journal of Agricultural Research, 4(2): 124-132.

Levine G 1982. Relative Water Supply: An Explanatory Variable for Irrigation System. Technical Report No:6, Cornell University, Ithaca, New York, USA.

Malano H, Burton M, Makin I 2004. Benchmarking Performance in the Irrigation and Drainage Sector: A Tool for Change. Irrigation and Drainage Irrig. and Drain., 53(2): 119-133.

Meinzen-Dick R 1995. Timeliness of Irrigation. Irrigation and Drainage System, 9: 371-387.

Molden DJ, Gates TK 1990. Performance Measures for Evaluation of Irrigation-Water-Delivery Systems. Journal of Irrigation and Drainage Engineering 116(6): 804-823.

Molden DJ, Sakthivadivel R, Perry CJ, Fraiture CD, Kloezen WH 1998. Indicators for Comparing Performance of Irrigated Agricultural Systems. IWMI, Research Report 20, Colombo, 26 p.

Nalbantoğlu G, Çakmak B 2007. Akıncı Sulama Birliğinde Sulama Performansının Karşılaştırmalı Değerlendirilmesi. A.Ü. Ziraat Fakültesi Tarım Bilimleri Dergisi 13(3): 213-223.

Phadnis SS, Kulsreshtha M 2011.Benchmarking as a Tool For Improvement of System Performance: Case of Samrat Ashok Sagar Irrigation Project, Madhya Pradesh, India. Journal of Environmental Research and Development, 5(4): 984-996. 
Plusquellec HL, McPhail K, Polti C 1990. Review of Irrigation SystemI with Respect to Initial Objectives. Irrigation and Drainage Systems, 4(4): 313-327.

Uçar Y 2011. Performance assessment irrigation schemes according to comparative indicators: A case study of Isparta, Turkey. European Journal of Scientific Research, 52(1): 82-90.

Vermillion DL 2000. Guide to Monitoring and Evaluation of Irrigation Management Transfer, International Network on Participatory Irrigation
Management (INPIM), USA.

Vermillion DL, Sagardoy JA 1999. Transfer of Irrigation Management Services: Guideline, FAO Irrigation and Drainage Paper 58, FAO, IWMI and GTZ, Rome.

Yercan M, Dorsan F, Ul M A 2004. Comparative Analysis of Performance Criteria in Irrigation Schemes: A Case Study of Gediz River Basin in Turkey. Agricultural Water Management, 66: 259266. 